\title{
Physicochemical, Thermal and Spectroscopic Characterization of the Energy of Consciousness Healing Treated Withania somnifera (Ashwagandha) Root Extract
}

\author{
Mahendra Kumar Trivedii ${ }^{1}$ and Snehasis Jana ${ }^{2 *}$ \\ ${ }^{1}$ Trivedi Global, Inc., Henderson, USA \\ ${ }^{2}$ Trivedi Science Research Laboratory Pvt. Ltd., Thane (West), Maharashtra, India
}

*Corresponding author: Snehasis Jana, Trivedi Science Research Laboratory Pvt. Ltd., Thane (West), Maharashtra, India, Tel: +91- 022-25811234; Email: publication@trivedisrl.com

\section{Research Article \\ Volume 5 Issue 1}

Received Date: January 19, 2021

Published Date: February 08, 2021

DOI: $10.23880 /$ jonam-16000296

\section{Abstract}

Ashwagandha root extract is widely used in nutraceutical preparations due to its broad range of pharmacological activities. The objective of this study was to analyse the impact of Biofield Energy Treatment (The Trivedi Effect ${ }_{\circledast}$ ) on the physicochemical, thermal and spectral properties of ashwagandha root extract by using various analytical techniques. The sample of ashwagandha root extract was divided into two parts in which one part was kept untreated and called as control sample; while the other part was provided with the Consciousness Energy Healing Treatment remotely by the Biofield Energy Healer, Mr. Mahendra Kumar Trivedi and termed as Biofield Energy Treated sample. The study reported that the particle size values at $\mathrm{d}_{10}$, $d_{50}, d_{90}$, and D $(4,3)$ in the Biofield Energy Treated sample was significantly decreased by $9.23 \%, 9.04 \%, 11.86 \%$, and $10.59 \%$, respectively compared with the control sample. Thus, the surface area of the treated sample was significantly increased by $10.75 \%$ compared to the control sample. The PXRD analysis showed that the control as well as the Biofield Energy Treated samples was amorphous in nature. The DSC analysis showed that the onset evaporation temperature and latent heat of vaporization were significantly altered by $2.18 \%$ and-10.29\%, respectively in the Biofield Energy Treated sample compared with the control sample. The TGA analysis indicated the four step thermal degradation of both the samples. The $1^{\text {st }}, 2^{\text {nd }}, 3^{\text {rd }}$, and $4^{\text {th }}$ steps of thermal degradation of the treated sample showed an alteration in the weight loss by $-6.59 \%, 1.97 \%,-1.80 \%$, and $-8.65 \%$, respectively along with $0.81 \%$ reduction in the total weight loss, compared with the control sample. Besides, the maximum thermal degradation temperature $\left(\mathrm{T}_{\max }\right)$ in the control sample was observed at $234.17^{\circ} \mathrm{C}$ and $365.12^{\circ} \mathrm{C}$ for the two broad peaks, which was decreased by $1.73 \%$ and $0.82 \%$, respectively compared to the control sample. The overall analysis suggests that the Energy of Consciousness Healing Treatment might enhance the solubility, absorption, and bioavailability profile of ashwagandha root extract along with altered thermal stability. Such altered properties might help in designing better pharmaceutical and nutraceutical preparations; thereby provide better therapeutic response against various diseases such as amnesia, arthritis, anxiety, cancer, impotence, neurodegenerative, and cardiovascular diseases.

Keywords: Withania somnifera; Biofield Energy Healing Treatment; Consciousness Energy Healing; The Trivedi Effect ${ }^{\circledR}$; PXRD; Particle Size; TGA; DSC 


\section{Introduction}

Withania somnifera (ashwagandha) commonly known as winter cherry, its root extract contain active metabolites i.e. withanolides possess a broad range of pharmacological activities. Ashwagandha as nutraceuticals supports the healthy energy levels, healthy mental cognition, cardiovascular health, and healthy endothelial function along with improved lipid profile. Ashwagandha root extract contains a wide array of nutrients and phytochemicals; thus, it is also used as a dietary supplement and for health restoration [1]. In addition, ashwagandha root and leaf extract is widely used in most of the Indian herbal pharmaceuticals and nutraceuticals for the treatment of various diseases due to its various bioactive compounds and thereby exerts significant biological activities. The plant extract and its bioactive compounds are used in the prevention and treatment of various disorders, such as arthritis, amnesia, anxiety, impotence, cancer, neurodegenerative, and cardiovascular diseases, and others [2]. In ancient time, it was used as a tonic to arrest the ageing process, rejuvenate the body and boost the defence against infectious disorders and also promote the longevity [3]. Ashwagandha is commonly found in market as fine sieved powder, which is generally consumed with water, ghee (clarified butter) or honey. It vitalizes mind and body, enhances brain and nervous function system and improves the memory. Besides, it maintains reproductive system function and promotes healthy sexual and reproductive balance [4]. It used as an important nutraceutical in stress relief [5], due to its powerful adaptogen nature, which was studied using a rat model of chronic stress [6,7]. Ashwagandha improves cell-mediated immunity and regulate body's defence as immunomodulatory against many diseases, potent antioxidant properties to fight against cellular damage caused by free radicals, and muscle strength [8]. Besides, literatures reported that withanolides such as withaferin $\mathrm{A}$, withanolide $\mathrm{D}$, withanolide $\mathrm{E}$, etc., possess significant anticancer, immunomodulating, neuroprotective, antiepileptic, antibacterial, adaptogenic, spermatogenic, anti-depression, anti-anxiety, hepato-protective, antiinflammatory, anti-arthritic, anti-microbial, hypoglycaemic, hypolipidemic, aphrodisiac, anti-ulcer, and many more actions in the body [9].

The Trivedi Effect ${ }^{\circledR}$-Energy of Consciousness Healing Treatment has been widely known now days for its influence on the drug properties that could be used in improving the solubility, dissolution and bioavailability profile of various pharmaceutical/nutraceutical compounds [10-12]. Biofield Energy is considered as a unique energy which is paradimensional and exists in the form of electromagnetic field around the human body. Based on Biofield (Putative Energy Fields) there are several Energy Healing Therapies in the world that are known to pose significant impacts against various disease conditions [13]. Thus, a human has the ability to harness energy from the earth and transmit it to any living or non-living object(s) around the globe [14]. Such energy therapies are included under the Complementary and Alternative Medicine (CAM) and also recommended by the National Institute of Health/National Center for Complementary and Alternative Medicine (NIH/NCCAM) due to their several advantages [15]. The Trivedi Effect ${ }^{\circledR}{ }_{-}$ Consciousness Energy Healing Treatment has also been reported for its astonishing ability to affect the characteristic properties of several pharmaceuticals $[16,17]$, nutraceuticals [18], organic compounds $[19,20]$, metals and ceramic [2123], improve the overall productivity of agricultural crops $[24,25]$, impacted the culture medium [26,27], skin health $[28,29]$, and the isotopic abundance ratio in the organic compounds [30-32]. Thus, the current study was designed to determine the impact of Biofield Energy Treatment (The Trivedi Effect ${ }^{\circledR}$ ) on the physicochemical, thermal and spectral properties of ashwagandha root extract by using various analytical techniques such as, particle size analysis (PSA), powder X-ray diffraction (PXRD), differential scanning calorimetry (DSC), thermogravimetric analysis (TGA)/ differential thermogravimetric analysis (DTG), UV-visible and FT-IR spectroscopy.

\section{Materials and Methods}

\section{Chemicals and Reagents}

Withania somnifera (Ashwagandha) root hydroalcoholic extract was purchased from Sanat Product Ltd., India. All other chemicals used in the experiment were of analytical grade available in India.

\section{Consciousness Energy Healing Treatment Strategies}

Ashwagandha root extract i.e., the test sample was divided into two parts. Among both parts, one portion was denoted as control sample that did not receive the Biofield Energy Treatment. Besides, the other part of ashwagandha root extract was considered as treated part that received the Energy of Consciousness Healing Treatment by a renowned Biofield Energy Healer, Mr. Mahendra Kumar Trivedi (USA), and named as the Biofield Energy Treated sample. In the process of Biofield Energy Treatment, the sample was kept under the standard laboratory conditions and the Biofield Energy Healer provided the Trivedi Effect ${ }^{\circledR}$ - Energy of Consciousness Healing Treatment to the sample, remotely, for 3 minutes through the Unique Energy Transmission process. On the other hand, the control ashwagandha root extract was subjected to "sham" healer under the similar laboratory conditions, who did not have any knowledge about the Biofield Energy Healing Treatment. Consequently, 


\section{Journal of Natural \& Ayurvedic Medicine}

the control as well as Biofield Energy Treated ashwagandha root extract samples were kept in similar sealed conditions and further characterized by using PSA, PXRD, DSC, TGA/ DTG, UV-Vis, and FT-IR techniques.

\section{Characterization}

\section{$>$ Particle Size Analysis (PSA)}

The particle size analysis was done using wet method, which involves the use of instrument, Malvern Mastersizer 3000 , UK. The instrument has a detection range between $0.01 \mu \mathrm{m}$ to $3000 \mu \mathrm{m}$ [33], and the method involves the filling of sample unit (Hydro MV) with light liquid paraffin oil, which acts as dispersant medium. The refractive index values for dispersant medium and samples were 0.0 and 1.47, respectively. Later on, it was stirred at $2500 \mathrm{rpm}$, and the measurement was taken twice after reaching obscuration in between $10 \%$ and $20 \%$, followed by averaging both measurements. The PS analysis provides data in the form of $d_{10} \mu \mathrm{m}, d_{50} \mu \mathrm{m}, d_{90} \mu \mathrm{m}$, and $D(4,3)$ values, representing the particle diameter corresponding to $10 \%, 50 \%$ and $90 \%$ of the cumulative distribution. The calculations were done by using software Mastersizer V3.50.

The percent change in particle size (d) for $d_{10}, d_{50}, d_{90}$ and $\mathrm{D}(4,3)$ was calculated using following equation 1 :

$$
\% \text { change in Particle size }=\frac{\left[\mathrm{d}_{\text {Treated }}-\mathrm{d}_{\text {control }}\right]}{\mathrm{d}_{\text {control }}} \times 100
$$

Where, $\mathrm{d}_{\text {Control }}$ and $\mathrm{d}_{\text {Treated }}$ are the particle size $(\mu \mathrm{m})$ for at below $10 \%$ level $\left(\mathrm{d}_{10}\right), 50 \%$ level $\left(\mathrm{d}_{50}\right)$, and $90 \%$ level $\left(\mathrm{d}_{90}\right)$ of the control and Biofield Energy Treated samples, respectively.

Percent change in surface area (S) was calculated using following equation 2 :

$$
\% \text { change in Particle size }=\frac{\left[\mathrm{d}_{\text {Treated }}-\mathrm{d}_{\text {control }}\right]}{\mathrm{d}_{\text {control }}} \times 100
$$

Where, $S_{\text {control }}$ and $S_{\text {Treated }}$ are the surface area of the control and Biofield Energy treated ashwagandha root extract, respectively.

\section{$>$ Powder X-ray Diffraction (PXRD) Analysis}

The PXRD analysis of the control and Biofield Energy Treated samples of ashwagandha root extract was done with the help of PANalytical X'Pert3 powder X-ray diffractometer, UK. In this, the copper line was used as the radiation source for diffracting the analyte at $0.154 \mathrm{~nm}$ X-ray wavelengths, which is running at $40 \mathrm{~mA}$ current and $45 \mathrm{kV}$ voltage. Also, the scanning rate for instrument was kept at $18.87^{\circ}$ / second over a $2 \theta$ range of $3-90^{\circ}$ and the ratio of $\mathrm{K} \alpha-2$ and $\mathrm{K} \alpha-1$ was 0.5 ( $\mathrm{k}$, equipment constant). The data produced by the instrument was collected with the help of X'Pert data collector and X'Pert high score plus processing software. It provides the data in the form of a chart of the Bragg angle (20) vs. intensity (counts per second), and a table providing information regarding the peak intensity counts, $d$ value $(\AA)$, full width half maximum (FWHM) $\left({ }^{\circ} 2 \theta\right)$, relative intensity (\%), and area (cts*o $2 \theta$ ). From this data, the crystallite size (G) was analyzed with the help of the Scherrer equation (3) as follows:

$$
G=k \lambda /(b \cos \theta)(3)
$$

Where, $\mathrm{k}$ is the equipment constant $(0.5), \lambda$ is the X-ray wavelength $(0.154 \mathrm{~nm})$; $\mathrm{b}$ in radians is the full-width at half of the peaks and $\theta$ is the corresponding Bragg angle.

Later on, the percent change in crystallite size (G) of ashwagandha root extract was calculated using following equation 4:

$$
\% \text { change in Crystallite size }=\frac{\left[\mathrm{G}_{\text {Treated }}-\mathrm{G}_{\text {control }}\right]}{\mathrm{G}_{\text {control }}} \times 100
$$

Where, $\mathrm{G}_{\text {Control }}$ and $\mathrm{G}_{\text {Treated }}$ are the crystallite size of the control and Biofield Energy Treated ashwagandha root extract samples, respectively.

\section{$>$ Differential Scanning Calorimetry (DSC)}

The DSC analysis of the samples was done under the dynamic nitrogen atmosphere with the help of DSC Q2000 differential scanning calorimeter, USA, at the flow rate of $50 \mathrm{~mL} / \mathrm{min}$. In this process, $2-4 \mathrm{mg}$ sample was weighed and sealed in Aluminum pans. Later on, the sample was equilibrated at $30^{\circ} \mathrm{C}$ followed by heating up to $450^{\circ} \mathrm{C}$ at the rate of $10^{\circ} \mathrm{C} / \mathrm{min}$ under nitrogen gas as purge atmosphere [34]. The thermogram reveals the value for onset, end set, peak temperature, peak height $(\mathrm{mJ}$ or $\mathrm{mW})$, peak area, and change in heat $(\mathrm{J} / \mathrm{g})$ for each peak. Later on, the percent change in melting temperature (T) of the control and Biofield Energy Treated samples was calculated using following equation 5 :

$$
\% \text { change in melting temperature }=\frac{\left[\mathrm{T}_{\text {Treated }}-\mathrm{T}_{\text {control }}\right]}{\mathrm{T}_{\text {control }}} \times 100
$$

Where, $\mathrm{T}_{\text {Control }}$ and $\mathrm{T}_{\text {Treated }}$ are the melting temperature of the control and Biofield Energy Treated ashwagandha root extract samples, respectively.

Also, the percent change in the latent heat of fusion $(\Delta \mathrm{H})$ was calculated using following equation 6 :

$$
\% \text { change in latent heat of fusion }=\frac{\left[\Delta \mathrm{H}_{\text {Treated }}-\Delta \mathrm{H}_{\text {control }}\right]}{\Delta \mathrm{H}_{\text {control }}} \times 100 \text { (6) }
$$

Where, $\Delta \mathrm{H}_{\text {Control }}$ and $\Delta \mathrm{H}_{\text {Treated }}$ are the latent heat of fusion of the control and Biofield Energy Treated ashwagandha root extract, respectively. 


\section{Journal of Natural \& Ayurvedic Medicine}

> Thermal Gravimetric Analysis (TGA) / Differential Thermogravimetric Analysis (DTG)

TGA/DTG analysis was done using TGA Q500 themoanalyzer apparatus, USA under dynamic nitrogen atmosphere $(50 \mathrm{~mL} / \mathrm{min})$. It involves heating the samples from $25^{\circ} \mathrm{C}$ to $800^{\circ} \mathrm{C}$ at the rate of $10^{\circ} \mathrm{C} / \mathrm{min}$ using platinum crucible [34]. In TGA analysis, the weight loss in gram as well as percent loss for each step was recorded from the thermogram with respect to the initial weight of the sample. Consequently, the DTG analysis revealed the thermogram from which, the onset, endset, peak temperature and integral area for each peak was recorded. The percent change in weight loss $(\mathrm{W})$ was calculated using following equation 7 :

$$
\% \text { changein weight loss }=\frac{\left[\mathrm{W}_{\text {Treated }}-\mathrm{W}_{\text {control }}\right]}{\mathrm{W}_{\text {control }}} \times 100
$$

Where, $\mathrm{W}_{\text {control }}$ and $\mathrm{W}_{\text {Treated }}$ are the weight loss of the control and Biofield Energy Treated samples, respectively.

Also, the percent change in maximum thermal degradation temperature $\left(\mathrm{T}_{\max }\right)(\mathrm{M})$ was calculated using following equation 8:

$$
\% \text { change in } \mathrm{T}_{\max }(\mathrm{M})=\frac{\left[\mathrm{M}_{\text {Treated }}-\mathrm{M}_{\text {control }}\right]}{\mathrm{M}_{\text {control }}} \times 100
$$

Where, $\mathrm{M}_{\text {Control }}$ and $\mathrm{M}_{\text {Treated }}$ are the $\mathrm{T}_{\text {max }}$ values of the control and Biofield Energy Treated ashwagandha root extract samples, respectively.

\section{$>$ Ultraviolet-visible Spectroscopy (UV-Vis) Analysis}

The UV-Vis spectral analysis of the control and Biofield Energy Treated ashwagandha root extract samples was done with the help of Shimadzu UV-2400PC SERIES with UV
Probe (Shimadzu, JAPAN). The spectrum was recorded in the wavelength range of 190-800 $\mathrm{nm}$ using $1 \mathrm{~cm}$ quartz cell having a slit width of $0.5 \mathrm{~nm}$. The absorbance spectra (in the range of 0.2 to 0.9 ) and wavelength of maximum absorbance $\left(\lambda_{\max }\right)$ were recorded.

\section{$>$ Fourier Transform Infrared (FT-IR) Spectroscopy}

FT-IR spectroscopy of ashwagandha root extract was done by using Spectrum ES Fourier transform infrared spectrometer (Perkin Elmer, USA) with the frequency array of $400-4000 \mathrm{~cm}^{-1}$. The process involves pressed $\mathrm{KBr}$ disk technique in which, $\sim 2 \mathrm{mg}$ of sample was taken along with about $300 \mathrm{mg}$ of $\mathrm{KBr}$ as the diluent, followed by forming the pressed disk and running the sample in the spectrometer.

\section{Results and Discussion}

\section{Particle Size Analysis (PSA)}

Particle size analysis was done for the control and Biofield Energy Treated ashwagandha root extract and the results are mentioned in Table 1 . The particle size distribution of the control sample was observed at $d_{10}(32.5 \mu \mathrm{m}), d_{50}(88.5$ $\mu \mathrm{m}), \mathrm{d}_{90}(194 \mu \mathrm{m})$, and $\mathrm{D}(4,3)(102 \mu \mathrm{m})$. Consequently, the particle size distribution of the Biofield Energy Treated sample at $\mathrm{d}_{10}, \mathrm{~d}_{50}, \mathrm{~d}_{90}$, and $\mathrm{D}(4,3)$ was found as $29.5 \mu \mathrm{m}, 80.5$ $\mu \mathrm{m}, 171 \mu \mathrm{m}$, and $91.2 \mu \mathrm{m}$, respectively. Thus, the analysis showed that the particle size values at $\mathrm{d}_{10}, \mathrm{~d}_{50}, \mathrm{~d}_{90}$, and $\mathrm{D}(4,3)$ in the Biofield Energy Treated ashwagandha root extract was significantly decreased by $9.23 \%, 9.04 \%, 11.86 \%$, and $10.59 \%$, respectively as compared with the control sample (Table 1). However, the surface area of the Biofield Energy Treated ashwagandha root extract $\left(101.50 \mathrm{~m}^{2} / \mathrm{g}\right)$ was observed to be significantly increased by $10.75 \%$ compared with the control sample $\left(91.65 \mathrm{~m}^{2} / \mathrm{g}\right)$.

\begin{tabular}{|c|c|c|c|c|c|}
\hline Test Item & $\mathbf{d}_{\mathbf{1 0}}(\boldsymbol{\mu m})$ & $\mathbf{d}_{\mathbf{5 0}}(\boldsymbol{\mu m})$ & $\mathbf{d}_{\mathbf{9 0}}(\boldsymbol{\mu m})$ & $\mathbf{D}(\mathbf{4 , 3})(\boldsymbol{\mu m})$ & $\mathbf{S S A}\left(\mathbf{m}^{\mathbf{2}} / \mathbf{K g}\right)$ \\
\hline Control sample & 32.5 & 88.5 & 194 & 102 & 91.65 \\
\hline Biofield Energy Treated sample $^{*}$ & 29.5 & 80.5 & 171 & 91.2 & 101.5 \\
\hline Percent change* (\%) $^{*}$ & -9.23 & -9.04 & -11.86 & -10.59 & 10.75 \\
\hline
\end{tabular}

Table 1: Particle size distribution of the control and Biofield Energy Treated W. somnifera (Ashwagandha) root extract. $\mathrm{d}_{10,} \mathrm{~d}_{50}$, and $\mathrm{d}_{90}$ : particle diameter corresponding to $10 \%, 50 \%$ and $90 \%$ of the cumulative distribution, $\mathrm{D}(4,3)$ : the average massvolume diameter, SSA : the specific surface area; ${ }^{*}$ denotes the percentage change in the particle size distribution of the Biofield Energy Treated sample with respect to the control sample.

The results indicated the impact of Biofield Energy Treatment on the physico-chemical properties of ashwagandha root extract. It was previously reported that the particle size, shape and surface area of the drug may pose their impact on the solubility, dissolution rate, bioavailability, and the therapeutic efficacy of the dosage form $[35,36]$. Also, the decreased size of the particle along with the increased surface area may also help in enhancing the solubility, absorption and bioavailability profile of drug [37]. Thus, it is anticipated that the Biofield Energy Treated ashwagandha root extract might show the enhanced absorption rate and thereby a better bioavailability profile as compared to the untreated sample. 


\section{Powder X-ray Diffraction (PXRD) Analysis}

PXRD study of the control and Biofield Energy Treated ashwagandha root extract was done to determine the crystalline pattern of the samples. The diffractograms of both the control and Biofield Energy Treated samples are given in Figure 1, and there was no any sharp diffraction peak in the diffractograms of both the samples. Thus, it revealed that both samples were amorphous in nature and the Biofield Energy Treatment might not affect the crystallinity and pattern of the ashwagandha root extract.
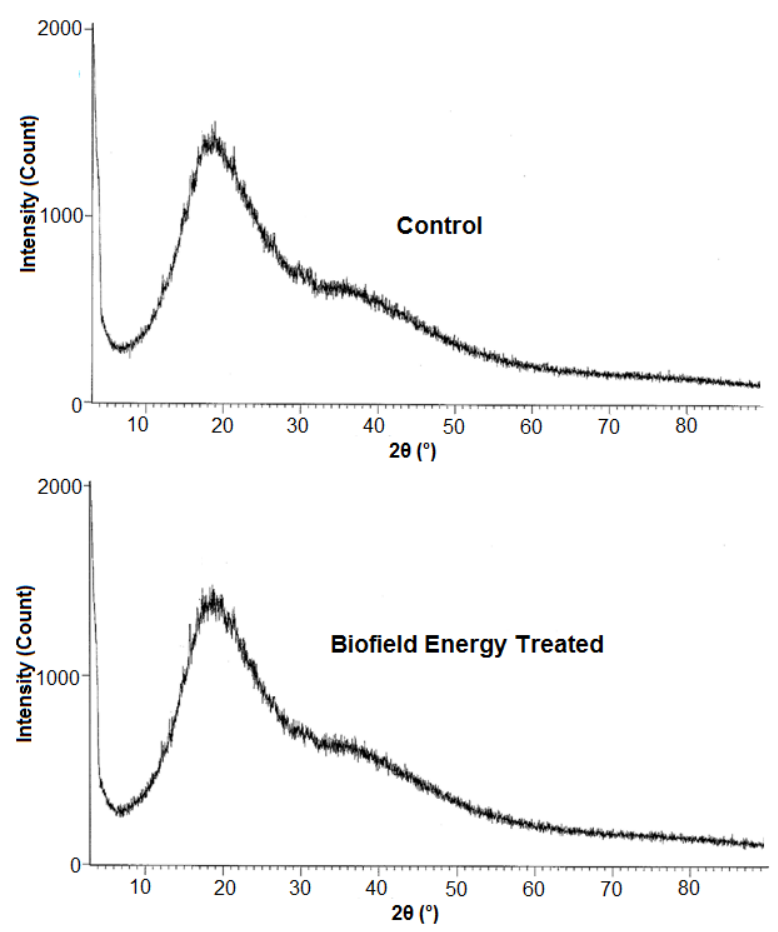

Figure 1: PXRD diffractograms of the control and Biofield Energy Treated $W$. somnifera (Ashwagandha) root extract.

\section{Differential Scanning Calorimetry Analysis}

(DSC)

The DSC thermograms of the control and Biofield Energy Treated ashwagandha root extract are given in Figure 2. The DSC thermograms of the control and Biofield Energy Treated samples showed a broad endothermic inflection at $80.64^{\circ} \mathrm{C}$ and $80.51^{\circ} \mathrm{C}$, respectively. This peak might be originated due to the evaporation of the bound water present in the samples. However, there was no significant difference observed in the evaporation temperature between the control and the Biofield Energy Traeted sample. Moreover, the onset evaporation temperature and the latent heat of vaporization in the Biofield Energy Treated sample were observed to be altered significantly by $2.18 \%$ and $-10.29 \%$, respectively, compared with the control sample (Table 2). Thus, it is assumed that the Biofield Energy Treatment might affected the intermolecular force, which probably resulted in the decreased heat change in the Biofield Energy Treated sample as compared to the control sample. Besides, the thermograms of both the samples also showed several endothermic peaks near $180^{\circ} \mathrm{C}$ (Figure 2), which might appeared as a result of presence of multiple phytoconstituents in small concentration in the root extract $[38,39]$.

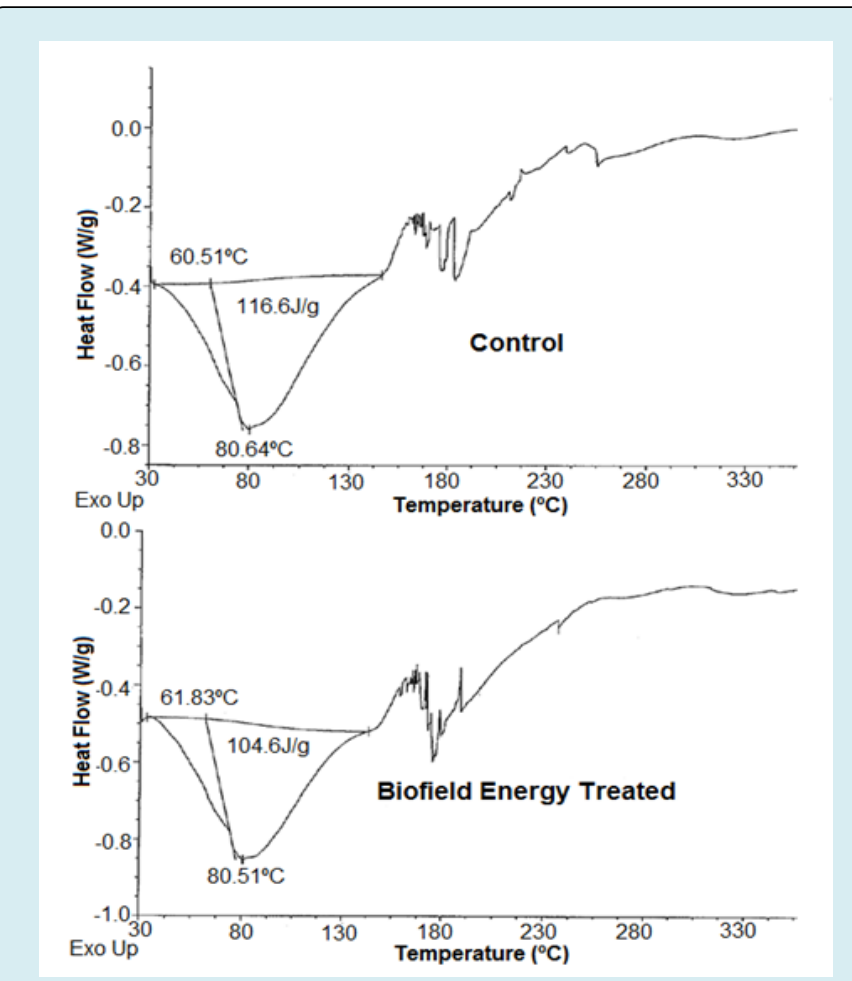

Figure 2: DSC thermograms of the control and Biofield Energy Treated W. somnifera (Ashwagandha) root extract.

\begin{tabular}{|c|c|c|c|}
\hline Sample & $\begin{array}{c}\mathbf{T}_{\text {onset }} \\
\left({ }^{\circ} \mathbf{C}\right)\end{array}$ & $\begin{array}{c}\mathbf{T}_{\text {peak }} \\
\left({ }^{\circ} \mathbf{C}\right)\end{array}$ & $\begin{array}{c}\Delta \mathbf{H}_{\text {vaporisation }} \\
(\mathbf{J} / \mathbf{g})\end{array}$ \\
\hline Control sample & 60.51 & 80.64 & 116.6 \\
\hline $\begin{array}{c}\text { Biofield Treated } \\
\text { sample }\end{array}$ & 61.83 & 80.51 & 104.6 \\
\hline \% Change* & 2.18 & -0.16 & -10.29 \\
\hline
\end{tabular}

Table 2: The melting point $\left({ }^{\circ} \mathrm{C}\right)$ and latent heat of fusion $(\mathrm{J} / \mathrm{G})$ values of the control and Biofield Energy Treated $W$. somnifera (Ashwagandha) root extract.

$\mathrm{T}_{\text {onset }}$ : Onset vaporization temperature, $\mathrm{T}_{\text {peak }}$ : Peak vaporization temperature, $\Delta \mathrm{H}$ : Latent heat of vaporization, * denotes the percentage change of the Biofield Energy Treated sample with respect to the control sample. 


\section{Thermal Gravimetric Analysis (TGA)/ Differential Thermogravimetric Analysis (DTG)}

The thermal stability studies of the control and Biofield Energy Treated ashwagandha root extracts was done by using TGA/DTG technique and the TGA thermograms of both the smaples showed four steps of thermal degradation (Figure 3 ). The analysis revealed that in the $1^{\text {st }}, 3^{\text {rd }}$, and $4^{\text {th }}$ steps of thermal degradation, the weight loss of the Biofield Energy Treated sample was significantly decreased by
$6.59 \%, 1.80 \%$, and $8.65 \%$, respectively compared with the control sample (Table 3). Although, the $2^{\text {nd }}$ step showed some increase in the weight loss of the Biofield Energy Traeted sample, but the total weight loss (76.99\%) was slightly reduced by $0.81 \%$ compared with the control sample $(77.62 \%)$. Thus, it is presumed that the thermal stability of the Biofield Energy Treated sample was increased after the Consciousness Energy Healing Treatment compared to the untreated sample.

\begin{tabular}{|c|c|c|c|c|c|}
\hline \multirow{2}{*}{ Step } & \multicolumn{2}{|c|}{ Temperature $\left({ }^{\circ} \mathrm{C}\right)$} & \multicolumn{2}{|c|}{ Weight loss \% } & \multirow{2}{*}{ \% Change* } \\
\hline & Control & Treated & Control & Treated & \\
\hline $1^{\text {st }}$ step of degradation & 200.64 & 200.64 & 12.45 & 11.63 & -6.59 \\
\hline $2^{\text {nd }}$ step of degradation & 400.27 & 400.98 & 43.76 & 44.62 & 1.97 \\
\hline $3^{\text {rd }}$ step of degradation & 600.6 & 600.6 & 17.25 & 16.94 & -1.8 \\
\hline $4^{\text {th }}$ step of degradation & 795.25 & 795.66 & 4.16 & 3.8 & -8.65 \\
\hline Total weight loss & - & - & 77.62 & 76.99 & -0.81 \\
\hline
\end{tabular}

Table 3: Thermal degradation steps of the control and Biofield Energy Treated W. somnifera (Ashwagandha) root extract. ${ }^{*}$ denotes the percentage change in the weight loss of Biofield Energy Treated sample with respect to the control sample.
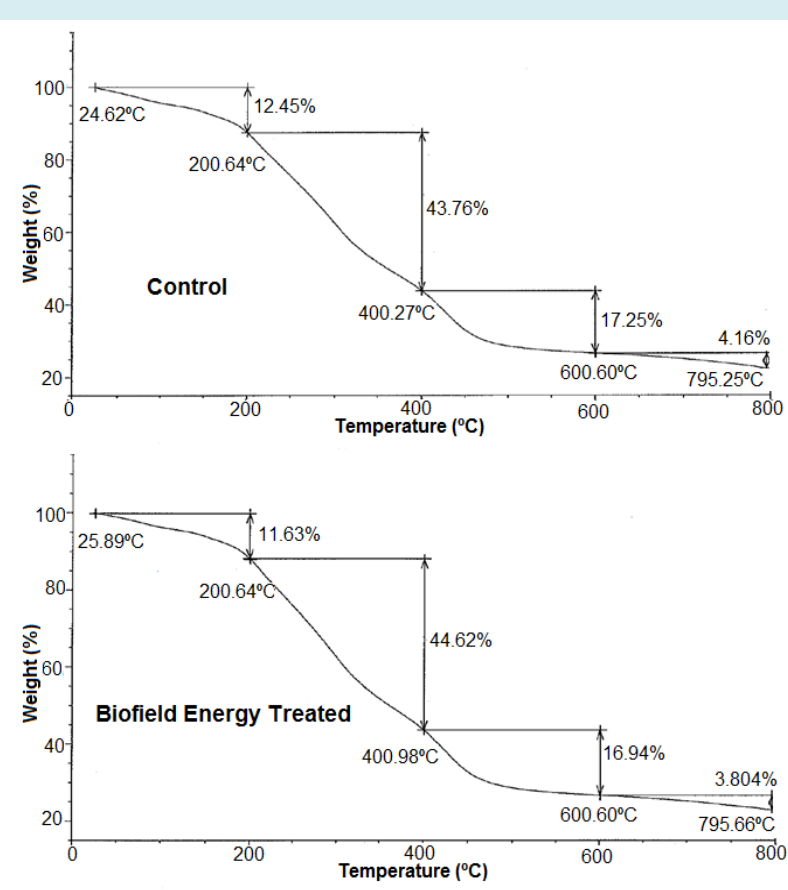

Figure 3: TGA thermograms of the control and Biofield Energy Treated W. somnifera (Ashwagandha) root extract.

Besides, the DTG thermograms of both the control and Biofield Energy Treated samples showed two broad peaks (Figure 4). The analysis revealed the maximum thermal degradation temperature in the control sample at $234.17^{\circ} \mathrm{C}$ and $365.12^{\circ} \mathrm{C}$ for these two broad peaks, however the Biofield Energy Treated sample showed $\mathrm{T}_{\max }$ at $230.11^{\circ} \mathrm{C}$ and $362.13^{\circ} \mathrm{C}$ corresponding to those peaks (Table 4 ).

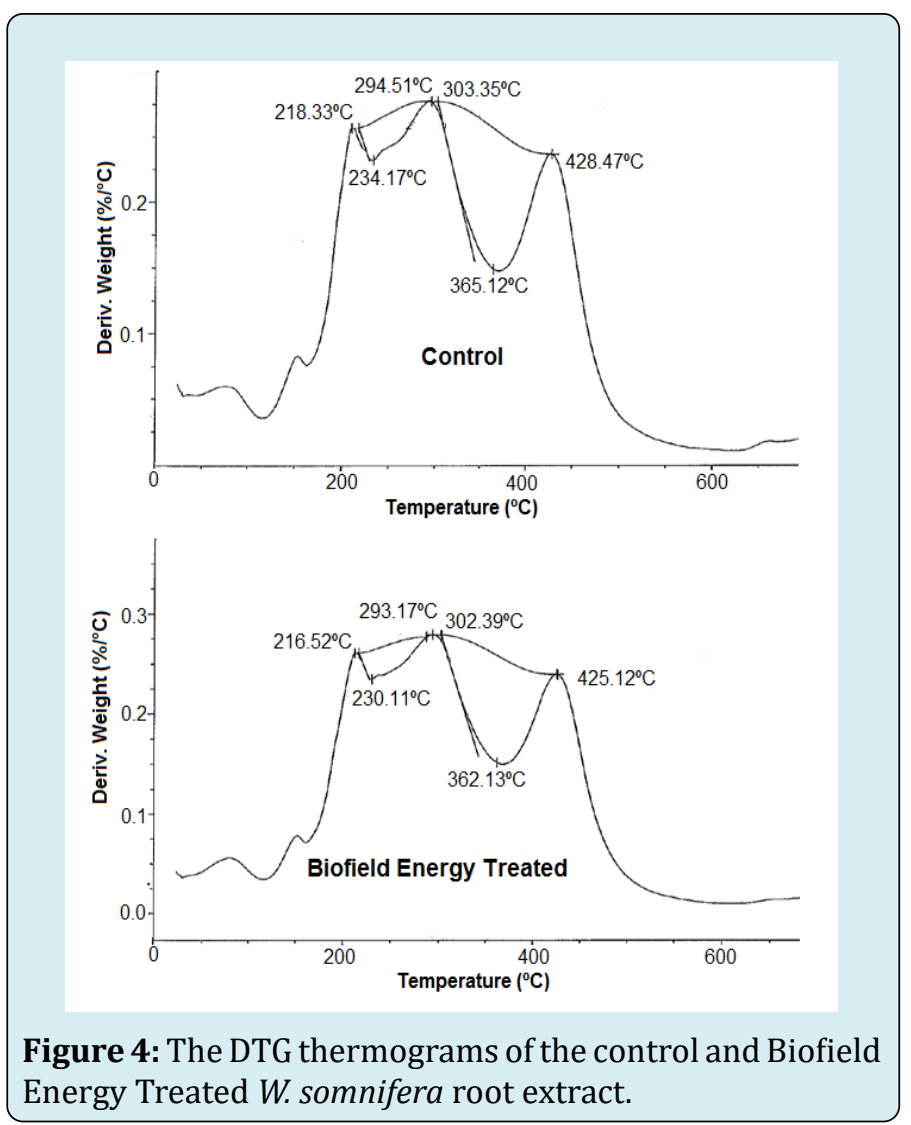


Thus, the $\mathrm{T}_{\max }$ of the Biofield Energy Treated sample was decreased by $1.73 \%$ and $0.82 \%$, respectively compared to the control the sample. Overall, the thermal studies indicated that the thermal stability of the Biofield Energy Treated ashwagandha root extract was altered compared to the control sample.

\begin{tabular}{|c|c|c|}
\hline \multirow{2}{*}{ Description } & \multicolumn{2}{|c|}{$\mathbf{T}_{\max }\left({ }^{\circ} \mathbf{C}\right)$} \\
\cline { 2 - 3 } & Peak 1 & Peak 2 \\
\hline Control Sample & 234.17 & 365.12 \\
\hline Biofield Energy Treated Sample & 230.11 & 362.13 \\
\hline \% Change* & -1.73 & -0.82 \\
\hline
\end{tabular}

Table 4: The DTG thermal degradation steps of the control and Biofield Energy Treated W. somnifera root extract.

"denotes the percentage change in the weight loss of the Biofield Energy Treated sample with respect to the control sample, $\mathrm{T}_{\max }=$ maximum thermal degradation temperature.

\section{Ultraviolet-visible Spectroscopy (UV-Vis) Analysis}

The UV-vis spectra of both the control and Biofield Energy Treated samples are shown in Figure 5.

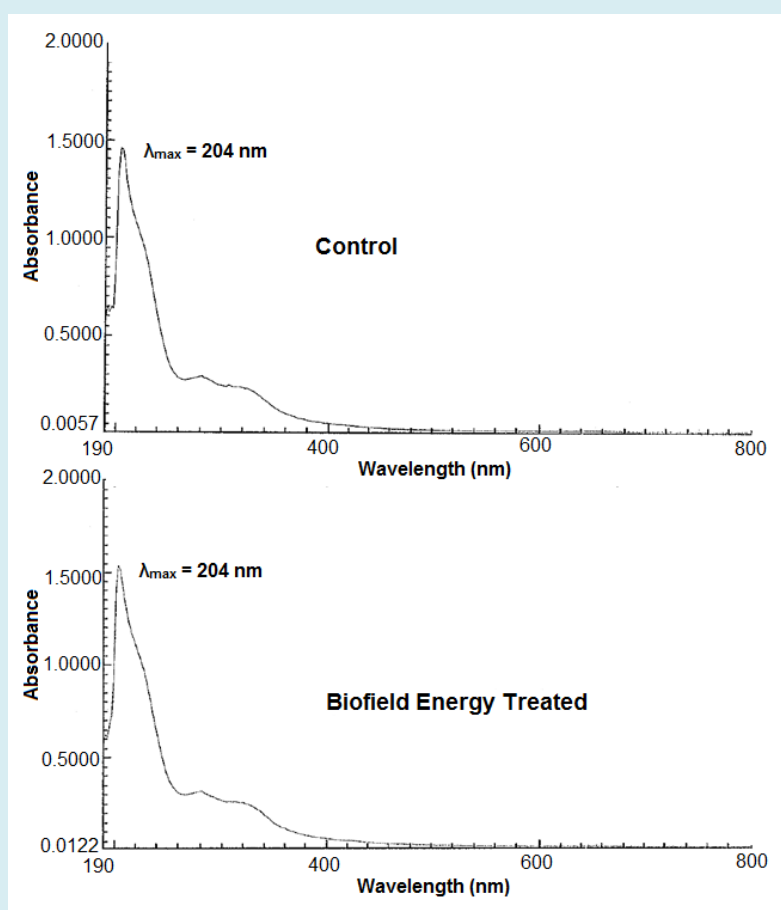

Figure 5: UV-vis spectra of the control and Biofield Energy Treated W. somnifera (Ashwagandha) root extracts.

The spectra of both the smaples showed the maximum absorbance at $204 \mathrm{~nm}\left(\lambda_{\max }\right)$. However, the peak at 204 $\mathrm{nm}$ was showed a minor shift of absorbance maxima from 1.4594 in control to 1.5376 in the Biofield Energy Treated sample. The UV absorbance occurs due to the different type of energy transitions and such electronic transitions only taken place when there is the energy difference between the lowest unoccupied molecular orbital (LUMO) and the highest occupied molecular orbital (HOMO) and it is significantly higher than the activation energy of the compound [40]. Thus, the UV-Vis studies revealed no difference in the control and Biofield Energy Treated sample in terms of $\lambda_{\max }$, which means that the molecular structure of the phytoconstituents in the Biofield Energy Treated sample remained same as that of the control sample.

\section{Fourier Transform Infrared (FT-IR) Spectroscopy}

The FT-IR spectra of the control and Biofield Energy Treated ashwagandha root extract are shown in Figure 6. It is reported that if other factors remain constant, the vibrational frequency (wavenumber) is directly proportional to the force constant; however, there are several factors that may affect it such as hybridization, bond strength, resonance, conjugation $[41,42]$.

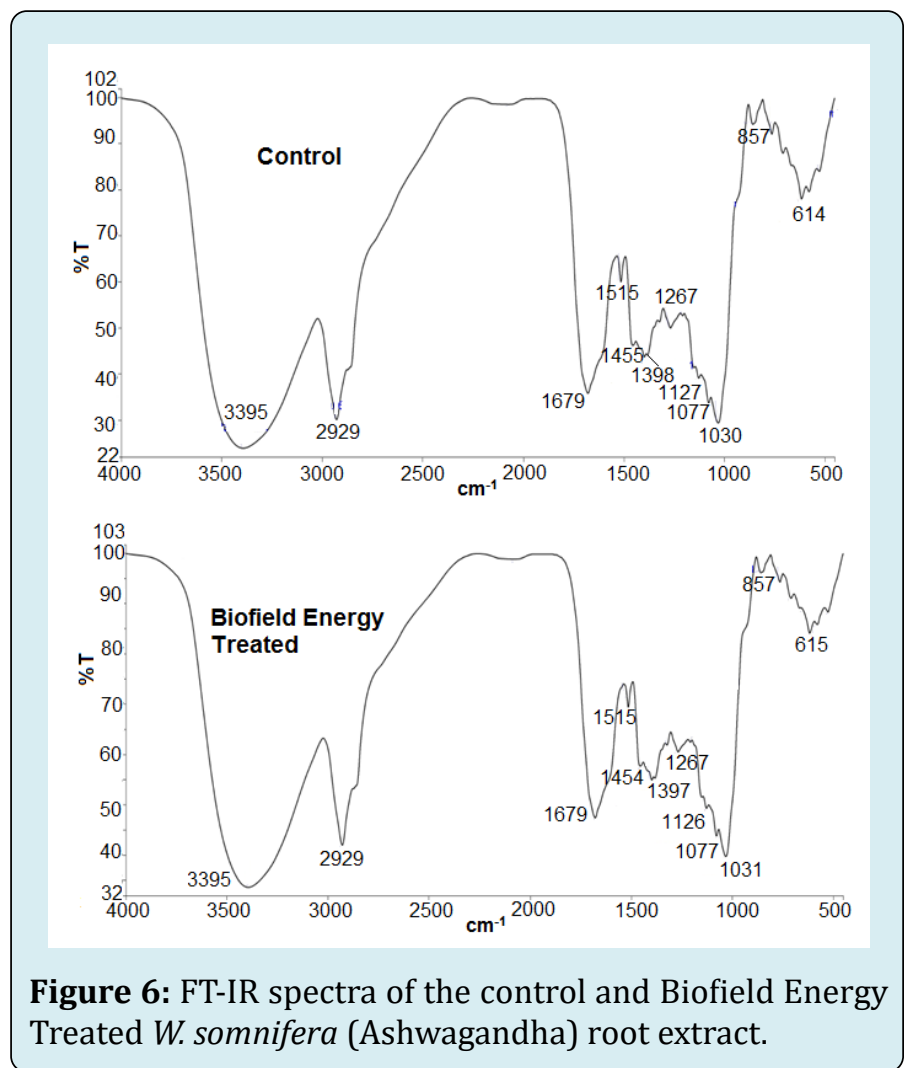

The FT-IR spectral analysis revealed that the vibrational frequencies of the Biofield Energy Treated sample corresponding to the characteristic functional 


\section{Journal of Natural \& Ayurvedic Medicine}

groups of ashwagandha root extract such as C-H, C-C, $\mathrm{C}-\mathrm{O}$, and $\mathrm{C}=\mathrm{O}$ groups were similar to the control sample. The broad peak at $3600-3200 \mathrm{~cm}^{-1}$ may be due to the $\mathrm{O}-\mathrm{H}$ functional group frequency of the hydroxyl groups present in phytoconstituents of the sample. The $\mathrm{O}-\mathrm{H}$ stretching was observed at $3395 \mathrm{~cm}^{-1}$ in both the samples. Similarly, the C-H stretching for both the samples was observed at $2929 \mathrm{~cm}^{-1}$. Moreover, the $\mathrm{C}=0$ stretching ( $\alpha, \beta$-unsaturated ketone) was observed at $1679 \mathrm{~cm}^{-1}$ in both the control and the Biofield Energy Treated sample. The peaks corresponding to C-C stretching in the spectra of control sample were observed at $1515,1455,1398$, and $1267 \mathrm{~cm}^{-1}$ and similarly these peaks were observed at 1515,1454,1397, and $1267 \mathrm{~cm}^{-1}$ in the spectra of the Biofield Energy Treated sample. Consequently, the peaks regarding C-O bonding (in alkoxy) were observed at 1127,1077 , and $1030 \mathrm{~cm}^{-1}$ in the control sample; while at 1126, 1077, and $1031 \mathrm{~cm}^{-1}$ in the Biofield Energy Treated sample. The peaks corresponding to $\mathrm{C}-\mathrm{H}$ aromatic bending were also similar in both the samples and were observed at 857 and $614 \mathrm{~cm}^{-1}$ in the control sample; while at 857 and 615 $\mathrm{cm}^{-1}$ in the Biofield Energy Treated sample. The presence of epoxide, unsaturated lactone, 1-keto-2-ene functional groups are very important regarding the pharmacological activities of withanolides [43-47]. However, the FT-IR results suggested that the spectra of both the samples remained same, which means there was no impact of Consciousness Energy Healing Treatment on the ashwagandha root extract at the atomic level to change the force constant of various atomic bonds.

\section{Conclusion}

The present study concluded the impact of Consciousness Energy Healing Treatment (The Trivedi Effect ${ }^{\circledR}$ ) on the physicochemical and thermal properties of the ashwagandha root extract. The particle size analysis showed that the particle size values at $d_{10}, d_{50}, d_{90}$, and $D(4,3)$ in the Biofield Energy Treated sample was significantly decreased by $9.23 \%$, $9.04 \%, 11.86 \%$, and $10.59 \%$, respectively as compared with the control sample. Moreover, the Biofield Energy Treated sample showed significant increase in the surface area by $10.75 \%$ compared to the control sample. The DSC analysis indicated that the onset evaporation temperature of the Biofield Energy Treated sample was significantly increased by $2.18 \%$ along with a reduction of $10.29 \%$ in the latent heat of vaporization compared with the control sample. The thermal stability analysis involving TGA data showed four steps of thermal degradation in both the control and Biofield Energy Treated samples of ashwagandha root extract. Among these steps, the $1^{\text {st }}, 3^{\text {rd }}$, and $4^{\text {th }}$ steps of thermal degradation of the treated sample showed reduction in the weight loss by $-6.59 \%,-1.80 \%$, and $-8.65 \%$, respectively; whereas the $2^{\text {nd }}$ step showed $1.97 \%$ increase in weight loss as compared to the control sample. Also, the total weight loss of the Biofield Energy Treated sample was slightly decreased by $0.81 \%$ compared to the control sample. Consequently, the DTG analysis revealed two broad peaks in both the samples in which, the $\mathrm{T}_{\max }$ for the control sample were observed at $234.17^{\circ} \mathrm{C}$ and $365.12^{\circ} \mathrm{C}$ for the two broad peaks. On the other hand, the Biofield Energy Treated sample corresponding to both peaks showed reduction of $1.73 \%$ and $0.82 \%$ compared to the control sample and were observed at $230.11^{\circ} \mathrm{C}$ and $362.13^{\circ} \mathrm{C}$, respectively. UV-vis analysis showed the similar $\lambda_{\max }$ for both the samples i.e. at $204 \mathrm{~nm}$. Overall, the Energy of Consciousness Healing Treated ashwagandha root extract might showed better dissolution, absorption, and bioavailability profile along with the increased thermal stability compared with the control sample. Thus, the Biofield Energy Treated ashwagandha root extract could be preferd to be used in the pharmaceutical and nutraceutical formulations that may be helpful in providing better therapeutic response against various diseases such as septic shock, impotency, confusion, low libido, diabetes mellitus, mood swings, stressrelated disorders insomnia, mental restlessness, depression, lack of motivation, migraines, obsessive/compulsive behavior, immunological and inflammatory diseases rheumatoid arthritis, irritable bowel syndrome, multiple sclerosis, Alzheimer's disease, osteoporosis, motor neurone disease, spinal muscular atrophy, chronic infections, etc.

\section{Acknowledgements}

The authors are grateful to GVK Biosciences Pvt. Ltd., Trivedi Science, Trivedi Global, Inc., and Trivedi Master Wellness for their assistance and support during this work.

\section{References}

1. Singh N, Bhalla M, Jager P, Gilca M (2011) An overview on ashwagandha: A rasayana (rejuvenator) of ayurveda. Afr J Tradit Complement Altern Med 8: 208-213.

2. Mishra LC, Singh BB, Dagenais S (2000) Scientific basis for the therapeutic use of Withania somnifera (ashwagandha): A review. Altern Med Rev 5(4): 334-346.

3. Misra L, Mishra P, Pandey A, Sangwan RS, Sangwan NS, et al. (2008) Withanolides from Withania somnifera roots. Phytochemistry 69(4): 1000-1004.

4. Dongre S, Langade D, Bhattacharyya S (2015) Efficacy and safety of ashwagandha (Withania somnifera) root extract in improving sexual function in women: A pilot study. Bio Med Research International.

5. Archana R, Namasivayam A (1998) Antistressor effect of Withania somnifera. J Ethnopharmacol 64(1): 91-93.

6. Bhattacharya S, Muruganandam A (2003) Adaptogenic activity of Withania somnifera: An experimental study 


\section{Journal of Natural \& Ayurvedic Medicine}

using a rat model of chronic stress. Pharmacol Biochem Behav 75(3): 547-555.

7. Provino R (2010) The role of adaptogens in stress management. Aust J Med Herbal 22(2): 41-49.

8. Wankhede S, Langade D, Joshi K, Sinha SR, Bhattacharyya S (2015) Examining the effect of Withania somnifera supplementation on muscle strength and recovery: A randomized controlled trial. Journal of the International Society of Sports Nutrition 12: 43.

9. Kumar V, Dey A, Hadimani MB, Marcović T, Emerald $M$ (2015) Chemistry and pharmacology of Withania somnifera: An update. Tang (Humanitas Medicine) 5(1): 1.1-1.13.

10. Trivedi MK, Branton A, Trivedi D, Nayak G, Balmer AJ, et al. (2017) Evaluation of physicochemical, thermal, structural, and behavioral properties of magnesium gluconate treated with energy of consciousness (The Trivedi Effect ${ }^{\circledR}$ ). Journal of Drug Design and Medicinal Chemistry 3(1): 5-17.

11. Trivedi MK, Branton A, Trivedi D, Nayak G, Balmer AJ, et al. (2017) Evaluation of physicochemical, spectral, thermal and behavioral properties of the biofield energy healing treated sodium selenate. Science Journal of Chemistry 5(2): 12-22.

12. Trivedi MK, Branton A, Trivedi D, Nayak G, Balmer AJ, et al. (2017) Study of the energy of consciousness healing treatment on physical, structural, thermal, and behavioral properties of zinc chloride. Modern Chemistry 5(2): 19-28.

13. Rubik B, Muehsam D, Hammerschlag R, Jain S (2015) Biofield science and healing: history, terminology, and concepts. Glob Adv Health Med 4: 8-14.

14. Zahra M, Farsi M (2009) Biofield therapies: Biophysical basis and biological regulations. Complement Ther Clin Pract 15(1): 35-37.

15. Barnes PM, Bloom B, Nahin RL (2008) Complementary and alternative medicine use among adults and children: United States, 2007. Natl Health Stat Report 12: 1-23.

16. Trivedi MK, Patil S, Shettigar H, Singh R, Jana S (2015) An impact of biofield treatment on spectroscopic characterization of pharmaceutical compounds. Mod Chem Appl 3(3): 159.

17. Trivedi MK, Branton A, Trivedi D, Nayak G, Bairwa K, et al. (2015) Spectroscopic characterization of disulfiram and nicotinic acid after biofield treatment. J Anal Bioanal Tech 6: 265.
18. Trivedi MK, Branton A, Trivedi D, Nayak G, Balmer AJ, et al. (2017) Evaluation of physicochemical, thermal, structural, and behavioral properties of magnesium gluconate treated with energy of consciousness (The Trivedi Effect $\left.{ }^{\mathbb{R}}\right)$. Journal of Drug Design and Medicinal Chemistry 3(1): 5-17.

19. Trivedi MK, Branton A, Trivedi D, Nayak G, Bairwa K, et al. (2015) Physical, thermal and spectroscopical characterization of biofield treated triphenylmethane: An impact of biofield treatment. J Chromatogr Sep Tech 6(6): 292.

20. Trivedi MK, Branton A, Trivedi D, Nayak G, Bairwa $\mathrm{K}$, et al. (2015) Physicochemical and spectroscopic characteristics of biofield treated $p$-chlorobenzophenone. American Journal of Physical Chemistry 4(6): 48-57.

21. Trivedi MK, Tallapragada RM, Branton A, Trivedi D, Nayak G, et al. (2015) The Potential impact of biofield energy treatment on the atomic and physical properties of antimony tin oxide nanopowder. American Journal of Optics and Photonics 3: 123-128.

22. Trivedi MK, Tallapragada RM, Branton A, Trivedi D, Nayak G, et al. (2015) Characterization of physical and structural properties of aluminium carbide powder: Impact of biofield treatment. J Aeronaut Aerospace Eng $4: 142$.

23. Trivedi MK, Tallapragada RM, Branton A, Trivedi D, Nayak G, et al. (2015) Physical, atomic and thermal properties of biofield treated lithium powder. J Adv Chem Eng 5: 136.

24. Trivedi MK, Branton A, Trivedi D, Nayak G, Mondal SC, et al. (2015) Impact of biofield energy treatment on soil fertility. Earth Sciences 4(6): 275-279.

25. Trivedi MK, Branton A, Trivedi D, Nayak G, Gangwar M, et al. (2015) Evaluation of vegetative growth parameters in biofield treated bottle gourd (Lagenaria siceraria) and okra (Abelmoschus esculentus). International Journal of Nutrition and Food Sciences 4: 688-694.

26. Trivedi MK, Branton A, Trivedi D, Nayak G, Bairwa K, et al. (2015) Physicochemical and spectroscopic properties of biofield energy treated protose. American Journal of Biomedical and Life Sciences 3: 104-110.

27. Trivedi MK, Branton A, Trivedi D, Nayak G, Bairwa K, et al. (2015) Effect of biofield treatment on physical, thermal, and spectral properties of SFRE 199-1 mammalian cell culture medium. Advances in Biochemistry 3: 77-85.

28. Dodon J, Trivedi MK, Branton A, Trivedi D, Nayak G, et 
al. (2017) The study of biofield energy treatment based herbomineral formulation in skin health and function. American Journal of Bio Science. 5(3): 42-53.

29. Kinney JP, Trivedi MK, Branton A, Trivedi D, Nayak G, et al. (2017) Overall skin health potential of the biofield energy healing based herbomineral formulation using various skin parameters. American Journal of Life Sciences 5(2): 65-74.

30. Trivedi MK, Branton A, Trivedi D, Nayak G, Saikia G, et al. (2015) Characterization of physico-chemical and spectroscopic properties of biofield energy treated 4-bromoacetophenone. American Journal of Physical Chemistry 4(4): 30-37.

31. Trivedi MK, Branton A, Trivedi D, Nayak G, Saikia G, et al. (2015) Quantitative determination of isotopic abundance ratio of ${ }^{13} \mathrm{C},{ }^{2} \mathrm{H}$, and ${ }^{18} \mathrm{O}$ in biofield energy treated ortho and meta toluic acid isomers. American Journal of Applied Chemistry 3(6): 217-223.

32. Trivedi MK, Branton A, Trivedi D, Nayak G, Saikia G, et al. (2015) Thermal, spectroscopic and chromatographic characterization of biofield energy treated benzophenone. Science Journal of Analytical Chemistry 3(6): 109-114.

33. Trivedi MK, Branton A, Trivedi D, Nayak G, Lee AC, et al. (2017) A comprehensive analytical evaluation of the Trivedi Effect ${ }^{\circledR}$ - Energy of Consciousness Healing Treatment on the physical, structural, and thermal properties of zinc chloride. American Journal of Applied Chemistry 5(1): 7-18.

34. Trivedi MK, Branton A, Trivedi D, Nayak G, Plikerd WD, et al. (2017) A systematic study of the biofield energy healing treatment on physicochemical, thermal, structural, and behavioral properties of iron sulphate. International Journal of Bioorganic Chemistry 2(3): 135145.

35. Chereson R (2009) Bioavailability, bioequivalence, and drug selection. In: Makoid CM, et al. (Eds.), Basic pharmacokinetics ( $1^{\text {st }}$ edn) Pharmaceutical Press, London.

36. Khadka P, Ro J, Kim H, Kim I, Kim JT, et al. (2014)
Pharmaceutical particle technologies: An approach to improve drug solubility, dissolution and bioavailability. Asian J Pharm Sci 9(6): 304-316.

37. Buckton G, Beezer AE (1992) The relationship between particle size and solubility. Int J Pharmaceutics 82(3): R7-R10.

38. Mitra D, Francis S, Varshney L (2004) Calorimetry thermal investigations on $\gamma$ radiation processed natural medicinal products (ashwagandha, amla and hartiki). J Therm Anal Cal 78: 821-829.

39. Srivastava A, Alam S, Shahbaaz S, Tiwari M, Mittal A, et al. (2014) Formulation and evaluation of antiacne cream containing Withania somnifera. J Pharm Sci Inv 3(4): 348- 352.

40. Hesse M, Meier H, Zeeh B (1997) Spectroscopic methods in organic chemistry, Georg Thieme Verlag Stuttgart, New York.

41. Stuart BH (2004) Infrared spectroscopy: Fundamentals and applications in analytical techniques in the sciences. John Wiley \& Sons Ltd., Chichester, UK.

42. Reichenbacher M, Popp J (2012) Challenges in Molecular structure determination, Springer-Verlag Berlin Heidelberg.

43. Zhao J, Nakamura N, Hattori M, Kuboyama T, Tohda C, et al. (2002) Withanolide derivatives from the roots of Withania somnifera and their neurite outgrowth activities. Chem Pharm Bull 50(6): 760-765.

44. Misra L, Lal P, Chaurasia ND, Sangwan RS, Sinha S, et al. (2008) Selective reactivity of 2-mercaptoethanol with $5 \beta, 6 \beta$ - epoxide in steroids from Withania somnifera. Steroids 73(3): 245-251.

45. Joshi P, Misra L, Siddique AA, Srivastava M, Kumar S, et al. (2014) Epoxide group relationship with cytotoxicity in withanolide derivatives from Withania somnifera. Steroids 79: 19-27.

46. Gu M, Yu Y, Gunaherath GMKB, Leslie Gunatilaka AA, Li D, et al. (2014) Structure-activity relationship (SAR) of withanolides to inhibit Hsp90 for its activity in pancreatic cancer cells. Invest New Drugs 32(1): 68-74. 